\title{
Potential mechanisms in fear of birth: The role of pain catastrophizing and intolerance of uncertainty
}

\author{
Elisabet Rondung MS \\ Department of Psychology, Mid Sweden \\ University, Östersund, Sweden \\ Correspondence \\ Elisabet Rondung, Department of \\ Psychology, Mid Sweden University, \\ Östersund, Sweden. \\ Email: elisabet.rondung@miun.se
}

\begin{abstract}
Background: Although many pregnant women experience fear, worry, or anxiety relating to the upcoming birth, little is known regarding the psychological mechanisms contributing to these experiences. In this study, we wanted to take a first step in trying to identify mechanisms of potential interest. The objective of this crosssectional study was thus to investigate pain catastrophizing, intolerance of uncertainty, positive worry beliefs, and cognitive avoidance as potential mechanisms predicting fear of birth among pregnant women.
\end{abstract}

Methods: A sample of 499 pregnant women, recruited in antenatal health care settings in 2 Swedish regions, completed the Fear of Birth Scale, along with measurements of the mechanisms of interest. Linear and logistic hierarchical regression analyses were used to investigate the extent to which pain catastrophizing, intolerance of uncertainty, positive worry beliefs, and cognitive avoidance predicted fear of birth, both as a continuous and a dichotomous measure.

Results: Logistic regression analysis showed high levels of pain catastrophizing and intolerance of uncertainty to be the best predictors of fear of birth, OR 3.49 (95\% CI 2.17-5.61) and OR 3.25 (95\% CI 2.00-5.27), respectively. Positive beliefs about worry and cognitive avoidance were both correlated with fear of birth as a continuous measure, but did not contribute to the logistic regression model.

Conclusions: Pain catastrophizing and intolerance of uncertainty were the most evident predictors of fear of birth. Although preliminary, the findings suggest that interventions targeting catastrophic cognitions and intolerance of uncertainty might be relevant to psychological treatment for fear, worry, or anxiety relating to giving birth.

\section{K E Y W O R D S}

fear of birth, intolerance of uncertainty, pain catastrophizing

\section{1 | INTRODUCTION}

Experiences of fear, worry, or anxiety relating to giving birth are common among pregnant women. Prevalence ratings of clinically relevant fear or anxiety vary widely, and in a recent meta-analysis, the worldwide pooled prevalence was estimated at $14 \% .^{1}$ In addition to causing emotional suffering during pregnancy, fear or anxiety of this kind has also been related to a more negative birth experience $e^{2,3}$ and worse psychological status postpartum. ${ }^{4}$ Although not consistent in the literature, negative medical consequences in terms of longer birth durations, ${ }^{5,6}$ higher rates of birth interventions, and cesarean delivery have also been shown., ${ }^{2,8}$

At present, a clear definition of this form of fear, worry, or anxiety is lacking. Several labels are used interchangeably in the literature, and the concept has been operationalized and measured in a variety of ways. Irrespective of label, the concept generally captures fears 
and anxieties, relating to pregnancy in general and childbirth in particular. ${ }^{9}$

Not surprisingly, fear or anxiety relating to giving birth has repeatedly been associated with other measures of anxiety, for example, general symptoms of anxiety ${ }^{10-12}$ and both state and trait anxiety. ${ }^{13-16}$ Results like these are highly relevant in showing that psychological factors, more than demographic factors or obstetric history, may contribute to birth-related fear or anxiety. This also emphasizes the need for psychological interventions in addition to medical approaches to reduce such fear or anxiety.

Psychological models of anxiety typically strive to describe the interplay between specific cognitive, emotional, and behavioral mechanisms, important for the development and maintenance of a specific form of anxiety. An increasing focus on the similarities between mental disorders has resulted in an ongoing search for transdiagnostic mechanisms, that is, mechanisms that are shared across a wide range of disorders, and that are causally related to the onset, development, maintenance, or recovery from these. ${ }^{17-19}$ Several transdiagnostic mechanisms have been suggested, for example, repetitive negative thinking (such as worry or rumination), catastrophic thinking, positive and negative metacognitive beliefs (eg, positive beliefs about worry) and avoidance. ${ }^{17,19,20}$ Understanding of the role of causal mechanisms like these is of key value for the development of effective interventions. With respect to childbirth-related fear or anxiety, very few studies in the field have tried to identify mechanisms in this sense, and both cognitive and behavioral mechanisms contributing to the etiology and maintenance of this form of anxiety are still largely unexplored. ${ }^{21}$

With this study, we wanted to take a first step in trying to identify mechanisms relevant to the understanding of childbirth-related fear or anxiety. In the search for potential mechanisms, we tried to relate the limited knowledge regarding psychological aspects of birth-related fear of anxiety, to mechanisms shown to be of importance for related forms of anxiety, preferably mechanisms identified as transdiagnostic.

Given the associations shown between childbirth fear and anxiety as a general personality trait, ${ }^{15,16}$ we were particularly interested in mechanisms known to be of importance in generalized anxiety. The intolerance of uncertainty model of generalized anxiety disorder ${ }^{22-24}$ builds on 4 main features; intolerance of uncertainty, positive beliefs about worry, poor problem orientation, and cognitive avoidanceall of them correlating with clinical worry. ${ }^{23}$ Positive beliefs about worry is an example of metacognitive beliefs, suggested as a definite transdiagnostic mechanism by Harvey et $\mathrm{al}^{17}$ and cognitive avoidance could be related to thought suppression which has been identified as a possible transdiagnostic process. ${ }^{17}$ At the heart of the intolerance of uncertainty model of generalized anxiety disorder lies the concept "intolerance of uncertainty," which has been defined as "the tendency for an individual to consider the possibility of a negative event occurring as unacceptable and threatening irrespective of the probability of its occurrence" 25 and suggested a transdiagnostic feature across anxiety disorders and depression. ${ }^{26-28}$ Since being pregnant inevitably means being in a state associated with uncertainty, individuals experiencing uncertainty as highly distressing are likely to experience some degree of anxiety relating to pregnancy and childbirth. In line with this, fear relating to the unpredictability and lack of control during childbirth has been found an evident theme of fear among childbearing women. ${ }^{29,30}$

Since fears relating to pain are commonly reported among pregnant women too, ${ }^{31,32}$ we also sought to investigate the predictive role of pain catastrophizing. Pain catastrophizing refers to "an exaggerated negative 'mental set' brought to bear during actual or anticipated pain experience." ${ }^{33}$ With regard to childbirth, the tendency to exaggerate the negative aspects of pain has been associated with higher ratings of both anticipated and experienced pain during childbirth. ${ }^{34}$ Pain catastrophizing has also been found to mediate the relationship between fear of pain and preference for cesarean delivery. ${ }^{35}$ Although pain catastrophizing is specifically focusing on pain-related cognitions, catastrophic beliefs in general have been suggested as a transdiagnostic mechanism across mental disorders. ${ }^{20}$

To our knowledge, none of these variables has previously been studied in relation to fear or anxiety of giving birth. Our aim with this study was thus to take a first step in trying to identify psychological mechanisms relevant to the understanding of childbirth-related fear or anxiety, beginning with investigating the extent to which pain catastrophizing, intolerance of uncertainty, positive beliefs about worry, and cognitive avoidance could predict fear of birth in a general pregnant population.

\section{2 | METHODS}

\section{1 | Design and participants}

Recruitment for this cross-sectional study was conducted by midwives working at 42 antenatal health care clinics in 2 Swedish regions, Regions Jämtland Härjedalen and Region Örebro County, during the period of January 1 to December 31,2015 . For a woman to be included, she needed to be Swedish speaking and in pregnancy week 18 or more with a normal routine ultrasound examination.

Out of 822 women reported as eligible, 4 were excluded because of nonnormal ultrasound results and 54 as a result of not speaking Swedish. Of the 764 women approached, 63 declined participation. While 701 consented to participate, 202 women failed to return the questionnaire. The final sample thus included 499 women. 
TA B L E 1 Characteristics of pregnant women in a study of fear of birth, Sweden, 2015

\begin{tabular}{|c|c|}
\hline Characteristic & n $(\%)$ \\
\hline \multicolumn{2}{|l|}{ Parity } \\
\hline Nulliparous & $227(45.6)$ \\
\hline Parous & $271(54.4)$ \\
\hline \multicolumn{2}{|l|}{ Civil status } \\
\hline Married or cohabiting & $487(98.6)$ \\
\hline Single or not living with partner & $7(1.4)$ \\
\hline \multicolumn{2}{|l|}{ Education } \\
\hline University & $292(58.5)$ \\
\hline Primary school or high school & $207(41.5)$ \\
\hline \multicolumn{2}{|l|}{ Occupational status } \\
\hline Employed & $380(76.8)$ \\
\hline Self-employed & $19(3.8)$ \\
\hline Studying & $31(6.2)$ \\
\hline On sick leave or pregnancy leave & $72(14.6)$ \\
\hline On maternity leave & $37(7.4)$ \\
\hline Unemployed & $19(3.8$ \\
\hline \multicolumn{2}{|l|}{ Country of birth } \\
\hline Sweden & $469(94.7)$ \\
\hline Other & $26(5.3)$ \\
\hline \multicolumn{2}{|l|}{ Self-reported obstetric complications } \\
\hline Preeclampsia & $2(0.4)$ \\
\hline Gestational diabetes & $1(0.2)$ \\
\hline Symphysis pubis dysfunction & $41(8.3)$ \\
\hline Placenta previa & $23(4.7)$ \\
\hline Vaginal bleeding & $8(1.6)$ \\
\hline Other complication & $73(14.6)$ \\
\hline Any complication & $134(26.9)$ \\
\hline Previous negative experiences in health care & $142(28.5)$ \\
\hline
\end{tabular}

Ethical approval was obtained from the regional ethical board in Umeå, Sweden (2014-372-31Ö).

\section{2 $\mid$ Measurements}

Besides demographics, the questionnaire included questions regarding the ongoing pregnancy (pregnancy week and currently experienced complications), previous childbirth experiences (mode of birth and year), and an open question regarding previous negative experiences in health care.

The Fear of Birth Scale, FOBS $S^{36,37}$ was used to measure self-reported fear of birth. In this 2-item Visual Analogue Scale, the question "How do you feel right now about the approaching birth?" is answered by marking on two 100-mm lines with the anchors "calm/worried" and "no fear/strong fear." A total fear of birth score is calculated by averaging the 2 ratings, with a mean of 60 or more indicating fear of birth. ${ }^{37,38}$ FOBS has shown good internal consistency and construct validity. ${ }^{36,39,40}$ In this study, Cronbach's alpha was .937 .

The Pain Catastrophizing Scale, $P C S^{41}$ was used to assess participants' degree of pain catastrophizing. The scale consists of 13 items in which the respondents rate, on a 5-point Likert scale (0-4), the extent to which they experience various thoughts and feelings in relation to actual or anticipated pain (eg, "When I'm in pain it's terrible and I think it's never going to get any better"). PCS has previously shown good internal consistency in pregnant populations. ${ }^{34}$ In this study, Cronbach's alpha was 937.

The Intolerance of Uncertainty Inventory part B, IUI-B, ${ }^{42}$ was used to capture cognitive and behavioral manifestations or consequences of intolerance of uncertainty (eg, "In an uncertain situation, I tend to exaggerate the odds that things will go badly," "I avoid situations in which something unanticipated is likely to occur," or "I worry a lot about life's uncertainties"). The 30 items were translated and back-translated to Swedish from the English version of the scale. Ratings were given on a 5-point Likert scale (1-5), and Cronbach's alpha was .972 .

Why Worry II, WW-II, ${ }^{24,43}$ with its 25 items, was used to measure positive worry beliefs. Ratings on items such as "If I worry, I will be less unhappy when a negative event occurs," "My worries can, by themselves, reduce the risk of danger," or "If I did not worry, I would be careless and irresponsible" are given on a 5-point Likert scale. This questionnaire was translated and back-translated from English to Swedish. Cronbach's alpha in this study was .942.

The Cognitive Avoidance Questionnaire, $C A Q^{44,45}$ is a 25-item self-report measure of the tendency to deal with intrusive threatening thoughts by employing cognitive avoidance strategies. The items (eg, "There are things I try not to think about" or "I distract myself to avoid thinking about certain disturbing things") are rated on a 5-point Likert scale. The questionnaire was translated and back-translated from English to Swedish. Cronbach's alpha in this study was .952.

\section{3 | Statistical analyses}

Data were analyzed using IBM SPSS Statistics 24 (Armonk, NY). As a result of nonnormal distributions, the MannWhitney $U$ test was used for comparisons between groups and Spearman's rho for correlational analysis. Reports of previous negative experiences in health care were dummy coded in the statistical analyses (having reported previous negative experiences or not). In all analyses, the significance level was set to $P<.05$.

Hierarchical linear regression analysis was performed to predict fear of birth as a continuous measure, using a 2step model. Primiparity was the only predictor entered in the first step (using the enter method). In the second step, the 


\begin{tabular}{|c|c|c|c|c|}
\hline & $\begin{array}{l}\text { Nulliparas } \\
(\mathrm{n}=\mathbf{2 2 7})\end{array}$ & $\begin{array}{l}\text { Multiparas } \\
(\mathrm{n}=\mathbf{2 7 1})\end{array}$ & & \\
\hline & Median & Median & $z$ & $r$ \\
\hline Fear of birth & 36.50 & 28.00 & $-2.18^{*}$ & -.10 \\
\hline Pain catastrophizing & 14.00 & 13.00 & -1.16 & -.05 \\
\hline Intolerance of uncertainty & 62.00 & 61.50 & -1.39 & -.06 \\
\hline Positive worry beliefs & 40.00 & 40.00 & -0.83 & -.04 \\
\hline Cognitive avoidance & 45.00 & 42.00 & -1.59 & -.07 \\
\hline
\end{tabular}

TABLE 2 Fear of birth and potential psychological mechanisms in nulliparous and multiparous women, Sweden, 2015

$z=z$-score of the Mann-Whitney $U$ statistic; $r=$ Pearson's $r$ effect size $(r=.10$ small effect; $r=.30$ medium effect; $r=.50$ large effect); ${ }^{*} P<.05 ; * * P<.01 ; * * * P<.001$ (Monte Carlo 2-tailed).

predictors pain catastrophizing, intolerance of uncertainty, positive worry beliefs, and cognitive avoidance were added to the model, using a stepwise approach. With such an approach, the entrance of predictors is determined statistically, only including variables that give a significant contribution to the model.

Hierarchical logistic regression analysis was used to predict a fear of birth score exceeding the cut point of FOBS $\geq 60$. In this analysis, the predictors were also dichotomized, using the fourth quartile of each scale as an indicator of high levels of pain catastrophizing (PCS 4th quartile), intolerance of uncertainty (IUI-B 4th quartile), positive worry beliefs (WW-II 4th quartile), and cognitive avoidance (CAQ 4th quartile). This regression model was built using the same 2 blocks as the linear model: (1) Primiparity, (2) 4th quartile of pain catastrophizing, intolerance of uncertainty, positive worry beliefs and cognitive avoidance. Once again, the enter method was used in the first block, while variables in the second block were entered stepwise (using the forward logistic regression method).

\section{3 | RESULTS}

The 499 pregnant women in this sample were between 19 and 45 years of age, with a mean age of 30.14 years $(\mathrm{SD}=5.03)$. Eighty percent of the participants were in gestational weeks 21-30, although the weeks of gestation ranged between 18 and 43 . In the sample, $45.6 \%$ were nulliparas and $54.4 \%$ multiparas. The vast majority of the participants were born in Sweden and lived with a partner (Table 1).

Nulliparous women reported slightly higher levels of fear of birth than did multiparous women, however with a small effect size (see Table 2). No other significant differences were found between the parity groups.

Using Spearman's rho for correlational analysis, fear of birth was positively correlated with pain catastrophizing $(\rho=.47, P<.001)$, intolerance of uncertainty $(\rho=.45$, $P<.001)$, positive worry beliefs $(\rho=.38, P<.001)$, and cognitive avoidance $(\rho=.36, P<.001)$.

A total of 122 women (24.6\%) scored above the cut point for fear of birth (FOBS $\geq 60$ ). When comparing women scoring above and below this cut point, women identified with fear of birth showed higher levels of pain catastrophizing, intolerance of uncertainty, positive worry beliefs, and cognitive avoidance, with small to medium effect sizes (Table 3).

Hierarchical multiple linear regression with fear of birth score as a continuous outcome variable did not identify primiparity as being a significant predictor of fear of birth. When entering the psychological variables, pain catastrophizing was the strongest predictor followed by intolerance of uncertainty and positive worry beliefs, in a model explaining $28 \%$ of the variance in fear of birth (Table 4).

Hierarchical multiple logistic regression with high levels of pain catastrophizing, intolerance of uncertainty, positive worry beliefs, and cognitive avoidance together with parity

\begin{tabular}{|c|c|c|c|c|}
\hline & $\begin{array}{l}\text { FOBS }<60 \\
(n=377)\end{array}$ & $\begin{array}{l}\text { FOBS } \geq 60 \\
(n=122)\end{array}$ & & \\
\hline & Median & Median & $z$ & $\mathbf{r}$ \\
\hline Pain catastrophizing & 11.00 & 21.00 & $-8.55^{* * *}$ & -.39 \\
\hline Intolerance of uncertainty & 58.00 & 80.00 & $-7.83^{* * *}$ & -.35 \\
\hline Positive worry beliefs & 38.00 & 45.00 & $-5.17^{* * *}$ & -.23 \\
\hline Cognitive avoidance & 41.00 & 52.00 & $-5.820^{* * *}$ & -.26 \\
\hline
\end{tabular}

T A B LE 3 Potential psychological mechanisms in pregnant women reporting different levels of fear of birth, Sweden, 2015

$z=z$-score of the Mann-Whitney $U$ statistic; $r=$ Pearson's $r$ effect size $(r=.10$ small effect; $r=.30$ medium effect; $r=.50$ large effect); $* P<.05 ; * * P<.01 ; * * * P<.001$ (Monte Carlo 2-tailed). 
TABLE 4 Hierarchical linear regression analysis predicting levels of fear of birth among pregnant women $(n=499)$, Sweden, 2015

\begin{tabular}{lllll} 
Predictor & Model 1 & Model 2 & Model 3 & Model 4 \\
\hline Nulliparity & .08 & .05 & .05 & .05 \\
\hline Pain catastrophizing & & $.50^{* * *}$ & $.36^{* * *}$ & $.365^{* * *}$ \\
\hline Intolerance of uncertainty & & & $.21^{* * *}$ & $.16^{* *}$ \\
\hline Positive worry beliefs & & & $.10^{*}$ \\
$R^{2}$ & .007 & .254 & .279 & .286 \\
$R^{2}$ change & .007 & $.247^{* * *}$ & $.025^{* * *}$ & $.008^{*}$ \\
\hline
\end{tabular}

$* P<.05 ; * * P<.01 ; * * * P<.001$. as predictors, showed high levels of pain catastrophizing and intolerance of uncertainty to be significant predictors of fear of birth above the cut point of FOBS $\geq 60$, while primiparity, positive worry beliefs, and cognitive avoidance did not contribute significantly to the model (Table 5).

\section{4 | DISCUSSION}

The aim of this study was to investigate pain catastrophizing, intolerance of uncertainty, positive beliefs about worry, and cognitive avoidance as potential mechanisms relevant to the understanding of childbirth-related fear or anxiety, while controlling for the significance of parity. In this general pregnant sample, women scoring positively for fear of birth (FOBS $\geq 60$ ) showed significantly higher self-reports on all 4 psychological variables. All variables were significantly correlated with fear of birth, and both pain catastrophizing and intolerance of uncertainty did significantly predict fear of birth both as a continuous and a dichotomous measure.

As suggested by Gellatly and Beck, ${ }^{20}$ catastrophic beliefs play a central role in a wide range of disorders, and may thus be seen as a transdiagnostic cognitive mechanism. In our analyses, pain catastrophizing was the strongest predictor of fear of birth in both regression analyses, explaining almost

T A B L E 5 Odds ratios (OR) and 95\% confidence intervals (CI) from hierarchical logistic regression analysis predicting fear of birth (FOBS $\geq 60)$ among pregnant women $(n=499)$, Sweden, 2015

\begin{tabular}{|cll|}
\hline Model & Predictor & OR $(\mathbf{9 5} \% \mathbf{C I})$ \\
\hline Block 1 & & \\
\hline Step 1 & Nulliparity & $1.17(0.78-1.76)$ \\
\hline Block 2 & & \\
\hline Step 1 & Nulliparity & $1.07(0.69-1.66)$ \\
& Pain catastrophizing & $4.98(3.20-7.76)^{* * *}$ \\
\hline Step 2 & Nulliparity & $0.99(0.63-1.55)$ \\
& $\begin{array}{l}\text { Pain catastrophizing } \\
\text { Intolerance of }\end{array}$ & $3.49(2.17-5.61)^{* * *}$ \\
& uncertainty & $3.25(2.00-5.27)^{* * *}$ \\
\hline
\end{tabular}

$* P<.05$; ** $P<.01$; *** $P<.001$.
$25 \%$ of the variance in fear when entered in the linear regression analysis. Pain catastrophizing pregnant women have previously been shown to give higher ratings of anticipated pain during childbirth. ${ }^{34}$ Increased levels of fear or anxiety regarding the approaching birth thus seem reasonable when anticipating it to be more painful, especially when interacting with catastrophic cognitions relating to the pain experience. Although the PCS is focused on catastrophizing in relation to actual or anticipated pain, ${ }^{41}$ we cannot be sure that the predictive association found between pain catastrophizing and fear of birth is not an effect of an overall tendency to engage in catastrophizing cognitions. This possibility thus needs further investigation.

Given the unpredictability inherent in expecting and giving birth to a child, we found the relation between intolerance of uncertainty and fear of birth to be of theoretical interest. With intolerance of uncertainty being central in the conceptualization of generalized anxiety disorder, ${ }^{22,23}$ and also suggested as a transdiagnostic feature across anxiety disorders and depression, ${ }^{26-28}$ this interest was further motivated by the previously reported associations between childbirth-related fear and both trait anxiety ${ }^{14-16}$ and anxiety diagnoses. ${ }^{46}$ Behavioral manifestations of intolerance of uncertainty did indeed turn out to be associated with fear of birth in this sample. While sharing variance with both pain catastrophizing and positive worry beliefs, a general tendency to find uncertainty as intolerable or distressing still seems to contribute to fear of birth.

Positive beliefs about worry predicted fear of birth as a continuous outcome, while only to a rather small extent. When dichotomized using the fourth quartile, the variable did not predict fear of birth exceeding the cut point of FOBS $\geq 60$. Cognitive avoidance on the other hand did not contribute significantly to any of the regression models. Among the investigated variables known to be of importance for clinical worry and generalized anxiety, intolerance of uncertainty was most strongly associated with fear of birth in this study. When taking a transdiagnostic perspective, our results point to the relevance of at least 2 potentially transdiagnostic mechanisms contributing to fear of birth, that is, intolerance of uncertainty and (pain-) catastrophizing cognitions.

As in previous research, ${ }^{38,47,48}$ nulliparous women reported slightly higher levels of fear of birth than did 
multiparous women. In the regression analyses however, nulliparity was not predictive of fear of birth. Hence, when comparing the importance of parity relative to pain catastrophizing and intolerance of uncertainty, our findings suggest the psychological variables to be of greater importance than parity in predicting childbirth-related fear, worry, or anxiety during pregnancy.

The most important strength of the study is its contribution to the common knowledge with respect to psychological concepts associated with childbirth-related fear, worry, or anxiety. As far as we know, it is the first study to specifically address pain catastrophizing and parameters known to be of importance in clinical worry (intolerance of uncertainty, positive beliefs about worry, and cognitive avoidance) in relation to this particular form of fear or anxiety. With this focus on psychological mechanisms, the findings may suggest intervention strategies of potential usefulness. However, this study also has several methodological limitations. As a result of its cross-sectional design, no causal relationships between concepts can be established. Another obvious limitation lies in the process of inclusion and exclusion. In this study, midwives working at many different antenatal health care clinics were asked to approach all pregnant women coming for their first antenatal health care visit after the routine ultrasound examination in gestational weeks 17-20. Unfortunately, the discrepancy between the annual birth rate in one of the regions, and the number of exclusions and nonconsents reported by the antenatal midwives in this region, indicate that all eligible women might not have been approached, or that exclusions and nonconsents were not reported as intended. As a result, the generalizability of the results may be somewhat reduced.

Although still far from a conceptual psychological model of childbirth-related fear, worry, or anxiety, the results of this study may have some clinical implications. To date, Sweden is one of few countries with an existing model of care for this form of fear. In addition to standard antenatal care, all hospitals in Sweden provide midwifeled counselling, with a specific focus on fear of birth. ${ }^{49}$ Although still sparingly evaluated, cognitive behavioral therapy has been suggested as an alternative and feasible approach. ${ }^{50}$ With regard to the concepts investigated in this study, this approach seems reasonable. Pain catastrophizing (or catastrophizing in general), as well as intolerance of uncertainty and positive beliefs about worry are all concepts commonly addressed in cognitive behavioral therapy. Cognitive behavioral interventions targeting these concepts (eg, by means of psychoeducation, selfmonitoring, Socratic questioning or cognitive restructuring, behavioral experiments, exposure with or without response prevention, techniques aiming at cognitive defusion and acceptance, and pain management techniques) may all be of relevance when meeting with women experiencing this form of fear, anxiety, or worry. Given the lack of established psychological models for this form of fear, worry, or anxiety, cognitive behavioral interventions provided by perinatal psychologists are likely to be most appropriate if based on a thorough individual assessment of the specific manifestations and the psychological factors contributing to fear for each woman.

\subsection{Conclusions}

The results of this study primarily suggest pain catastrophizing and intolerance of uncertainty to be potential mechanisms contributing to childbirth-related fear, anxiety, or worry. Until replicated, these findings are best viewed as preliminary. Interesting extensions in future research would be to look further into the distinction between pain catastrophizing and catastrophizing in general, investigating the concepts in larger samples to examine potential subgroups with specific response patterns, and of course to identify other concepts or mechanisms contributing to childbirth-related fear, worry, or anxiety.

\section{ORCID}

Elisabet Rondung (iD) http://orcid.org/0000-0001-5109-106X

Johanna Ekdahl (D) http://orcid.org/0000-0003-3293-6391

Örjan Sundin (D) http://orcid.org/0000-0002-4116-5501

\section{REFERENCES}

1. O'Connell MA, Leahy-Warren P, Khashan AS, Kenny LC, O'Neill SM. Worldwide prevalence of tocophobia in pregnant women: systematic review and meta-analysis. Acta Obstet Gynecol Scand. 2017;96:907-920.

2. Handelzalts JE, Becker G, Ahren M-P, et al. Personality, fear of childbirth and birth outcomes in nulliparous women. Arch Gynecol Obstet. 2015;291:1055-1062.

3. Larsson B, Karlström A, Rubertsson C, Hildingsson I. The effects of counseling on fear of childbirth. Acta Obstet Gynecol Scand. 2015;94:629-636.

4. Sieber S, Germann N, Barbir A, Ehlert U. Emotional well-being and predictors of birth-anxiety, self-efficacy, and psychosocial adaptation in healthy pregnant women. Acta Obstet Gynecol Scand. 2006;85:1200-1207.

5. Adams SS, Eberhard-Gran M, Eskild A. Fear of childbirth and duration of labour: a study of 2206 women with intended vaginal delivery. BJOG Int J Obstet Gynaecol. 2012;119:1238-1246.

6. Reck C, Zimmer K, Dubber S, Zipser B, Schlehe B, Gawlik $\mathrm{S}$. The influence of general anxiety and childbirth-specific anxiety on birth outcome. Arch Womens Ment Health. 2013;16:363-369.

7. Räisänen S, Lehto SM, Nielsen HS, Gissler M, Kramer MR, Heinonen S. Fear of childbirth in nulliparous and multiparous women: a population-based analysis of all singleton births in Finland in 1997-2010. BJOG Int J Obstet Gynaecol. 2014;121:965-970. 
8. Ryding EL, Lukasse M, Van Parys A-S, et al. Fear of childbirth and risk of cesarean delivery: a cohort study in six European countries. Birth Issues Perinat Care. 2015;42:48-55.

9. Nilsson C, Hessman E, Sjöblom H, et al. Definitions, measurements and revalence of fear of childbirth: a systematic review. BMC Pregnancy Childbirth. 2018;18:28.

10. Garthus-Niegel S, Størksen HT, Torgersen L, Von Soest T, Eberhard-Gran M. The Wijma Delivery Expectancy/Experience Questionnaire-a factor analytic study. J Psychosom Obstet Gynecol. 2011;32:160-163.

11. Laursen M, Hedegaard M, Johansen C. Fear of childbirth: predictors and temporal changes among nulliparous women in the Danish National Birth Cohort. BJOG Int J Obstet Gynaecol. 2008;115:354-360.

12. Rubertsson C, Hellström J, Cross M, Sydsjö G. Anxiety in early pregnancy: prevalence and contributing factors. Arch Womens Ment Health. 2014;17:221-228.

13. Alipour Z, Lamyian M, Hajizadeh E, Vafaei MA. The association between antenatal anxiety and fear of childbirth in nulliparous women: a prospective study. Iran J Nurs Midwifery Res. 2011;16:169-173.

14. Heimstad R, Dahloe R, Laache I, Skogvoll E, Schei B. Fear of childbirth and history of abuse: implications for pregnancy and delivery. Acta Obstet Gynecol Scand. 2006;85:435-440.

15. Molgora S, Fenaroli V, Prino LE, et al. Fear of childbirth in primiparous Italian pregnant women: the role of anxiety, depression, and couple adjustment. Women Birth J Aust Coll Midwives. 2018;31:117-123.

16. Pazzagli C, Laghezza L, Capurso M, Sommella C, Lelli F, Mazzeschi C. Antecedents and consequences of fear of childbirth in nulliparous and parous women. Infant Ment Health J. 2015;36:62-74.

17. Harvey AG. Cognitive Behavioural Processes across Psychological Disorders: A Transdiagnostic Approach to Research and Treatment. Oxford: Oxford University Press; 2004.

18. Sauer-Zavala S, Gutner CA, Farchione TJ, Boettcher HT, Bullis JR, Barlow DH. Current definitions of "transdiagnostic" in treatment development: a search for consensus. Behav Ther. 2017;48:128-138.

19. Watkins E. An alternative transdiagnostic mechanistic approach to affective disorders illustrated with research from clinical psychology. Emot Rev. 2015;7:250-255.

20. Gellatly R, Beck AT. Catastrophic thinking: a transdiagnostic process across psychiatric disorders. Cogn Ther Res. 2016;40:441-452.

21. Rondung E, Thomtén J, Sundin Ö. Psychological perspectives on fear of childbirth. J Anxiety Disord. 2016;44:80-91.

22. Dugas MJ, Gagnon F, Ladouceur R, Freeston MH. Generalized anxiety disorder: a preliminary test of a conceptual model. Behav Res Ther. 1998;36:215-226.

23. Dugas MJ, Marchand A, Ladouceur R. Further validation of a cognitive-behavioral model of generalized anxiety disorder: diagnostic and symptom specificity. J Anxiety Disord. 2005;19:329-343.

24. Freeston MH, Rhéaume J, Letarte H, Dugas MJ, Ladouceur R. Why do people worry? Personal Individ Differ. 1994; 17:791-802.

25. Carleton RN, Sharpe D, Asmundson GJG. Anxiety sensitivity and intolerance of uncertainty: requisites of the fundamental fears? Behav Res Ther. 2007;45:2307-2316.
26. Carleton RN, Mulvogue MK, Thibodeau MA, McCabe RE, Antony MM, Asmundson GJG. increasingly certain about uncertainty: intolerance of uncertainty across anxiety and depression. $J$ Anxiety Disord. 2012;26:468-479.

27. Gentes EL, Ruscio AM. A meta-analysis of the relation of intolerance of uncertainty to symptoms of generalized anxiety disorder, major depressive disorder, and obsessive-compulsive disorder. Clin Psychol Rev. 2011;31:923-933.

28. McEvoy PM, Mahoney AEJ. To be sure, to be sure: intolerance of uncertainty mediates symptoms of various anxiety disorders and depression. Behav Ther. 2012;43:533-545.

29. Fenwick J, Gamble J, Nathan E, Bayes S, Hauck Y. Pre- and postpartum levels of childbirth fear and the relationship to birth outcomes in a cohort of Australian women. J Clin Nurs. 2009; 18:667-677.

30. Fisher C, Hauck Y, Fenwick J. How social context impacts on women's fears of childbirth: a Western Australian example. Soc Sci Med. 1982;2006:64-75.

31. Geissbuehler V, Eberhard J. Fear of childbirth during pregnancy: a study of more than 8000 pregnant women. J Psychosom Obstet Gynecol. 2002;23:229-235.

32. Ryding EL, Wirfelt E, Wängborg I-B, Sjögren B, Edman G. Personality and fear of childbirth. Acta Obstet Gynecol Scand. 2007;86:814-820.

33. Sullivan MJL, Thorn B, Haythornthwaite JA, et al. Theoretical perspectives on the relation between catastrophizing and pain. Clin J Pain. 2001;17:52-64.

34. Flink IK, Mroczek MZ, Sullivan MJL, Linton SJ. Pain in childbirth and postpartum recovery - the role of catastrophizing. Eur J Pain. 2009;13:312-316.

35. Dehghani M, Sharpe L, Khatibi A. Catastrophizing mediates the relationship between fear of pain and preference for elective caesarean section. Eur J Pain. 2014;18:582-589.

36. Haines H, Pallant JF, Karlström A, Hildingsson I. Cross-cultural comparison of levels of childbirth-related fear in an Australian and Swedish sample. Midwifery. 2011;27:560-567.

37. Hildingsson I, Haines H, Karlstrom A, Nystedt A. Presence and process of fear of birth during pregnancy-findings from a longitudinal cohort study. Women Birth J Aust Coll Midwives. 2017;30:e242-e247.

38. Ternström E, Hildingsson I, Haines H, Rubertsson C. Higher prevalence of childbirth related fear in foreign born pregnant women-findings from a community sample in Sweden. Midwifery. 2015;31:445-450.

39. Haines HM, Pallant JF, Fenwick J, et al. Identifying women who are afraid of giving birth: a comparison of the fear of birth scale with the WDEQ-A in a large Australian cohort. Sex Reprod Healthc Off J Swed Assoc Midwives. 2015;6:204-210.

40. Ternström E, Hildingsson I, Haines H, Rubertsson C. Pregnant women's thoughts when assessing fear of birth on the Fear of Birth Scale. Women Birth. 2016;29:e44-e49.

41. Sullivan MJL, Bishop SR, Pivik J. The Pain Catastrophizing Scale: development and validation. Psychol Assess. 1995;7: 524-532.

42. Gosselin P, Ladouceur R, Evers A, Laverdière A, Routhier S, Tremblay-Picard M. Evaluation of intolerance of uncertainty: development and validation of a new self-report measure. J Anxiety Disord. 2008;22:1427-1439. 
43. Hebert EA, Dugas MJ, Tulloch TG, Holowka DW. Positive beliefs about worry: a psychometric evaluation of the Why Worry-II. Personal Individ Differ. 2014;56:3-8.

44. Gosselin P, Langlois F, Freeston MH, Ladouceur R, Dugas MJ, Pelletier O. Le Questionnaire d'Évitement Cognitif (QEC) : développement et validation auprès d'adultes et d'adolescents. $J$ Thérapie Comport Cogn. 2002;12:24-37.

45. Sexton KA, Dugas MJ. The Cognitive Avoidance Questionnaire: validation of the English translation. $J$ Anxiety Disord. 2008;22:355-370.

46. Rouhe H, Salmela-Aro K, Gissler M, Halmesmaeki E, Saisto T. Mental health problems common in women with fear of childbirth. BJOG Int J Obstet Gynaecol. 2011;118:1104-1111.

47. Nieminen K, Stephansson O, Ryding EL. Women's fear of childbirth and preference for cesarean section-a cross-sectional study at various stages of pregnancy in Sweden. Acta Obstet Gynecol Scand. 2009;88:807-813.
48. Rouhe H, Salmela-Aro K, Halmesmaeki E, Saisto T. Fear of childbirth according to parity, gestational age, and obstetric history. BJOG Int J Obstet Gynaecol. 2009;116:67-73.

49. Larsson B, Karlstrom A, Rubertsson C, Hildingsson I. Counseling for childbirth fear-a national survey. Sex Reprod Healthc Off J Swed Assoc Midwives. 2016;8:82-87.

50. Nieminen K, Andersson G, Wijma B, Ryding E-L, Wijma K. Treatment of nulliparous women with severe fear of childbirth via the Internet: a feasibility study. J Psychosom Obstet Gynecol. 2016;37:37-43.

How to cite this article: Rondung E, Ekdahl J, Sundin Ö. Potential mechanisms in fear of birth: The role of pain catastrophizing and intolerance of uncertainty. Birth. 2019;46:61-68. https://doi.org/10.1111/birt.12368 